\title{
Chronic inhibition of cyclic GMP phosphodiesterase 5A may promote pressure overload-induced chamber dilatation in mice Elisabeth Eder*1, Martin van Eickels ${ }^{2}$, Stefan Frantz ${ }^{3}$, Katharina Völker ${ }^{1}$, Hideo A Baba ${ }^{4}$ and Michaela Kuhn ${ }^{1}$
}

\author{
Address: 'Institute of Physiology, University of Wuerzburg, Wuerzburg, Germany, 2Institute of Physiology, University of Bonn, Bonn, Germany, \\ ${ }^{3}$ Department of Internal Medicine, University of Wuerzburg, Wuerzburg, Germany and ${ }^{4}$ Institute of Pathology, University of Duisburg-Essen; \\ Essen, Germany \\ Email: Elisabeth Eder* - eder-elisabeth@web.de \\ * Corresponding author
}

\author{
from $3^{\text {rd }}$ International Conference on cGMP Generators, Effectors and Therapeutic Implications \\ Dresden, Germany. 15-17 June 2007 \\ Published: 25 July 2007 \\ BMC Pharmacology 2007, 7(SuppI I):PI7 doi:I0.II86/I47I-22I0-7-SI-PI7
}

This abstract is available from: http://www.biomedcentral.com/I47I-22I0/7/SI/PI7

(c) 2007 Eder et al; licensee BioMed Central Ltd.

\section{Background}

Synthesis of cGMP in cardiomyocytes is stimulated by natriuretic peptides via GC-A signalling as well as nitric oxide (NO) via soluble guanylyl cyclase (sGC).

Different studies in vitro/in vivo have demonstrated that cGMP can inhibit myocardial hypertrophic responses. In particular, genetic ablation of the ANP/GC-A or NO/sGC systems in mice led to exacerbated cardiac hypertrophy in response to pressure overload. Conversely, inhibition of cGMP catabolism with the PDE5 inhibitor sildenafil prevented and even reversed pathological cardiac hypertrophy after aortic banding [1].

The present ongoing study was originally designed to elucidate whether the antihypertrophic effects of PDE5 inhibition are linked to the formation of cGMP by either the NP/GC-A or the NO/sGC system.

\section{Methods}

We subjected male C57Bl/ 6 mice ( 8 weeks of age, Charles River) to constriction of the transverse aorta (TAC) for 4 weeks. They were concurrently treated with the PDE5 inhibitor sildenafil $(100 \mathrm{mg} / \mathrm{kg} / \mathrm{d})$ or vehicle mixed in solid food ( $n=7$ per group). Heart function was examined by Echocardiography before and at 2 and 4 weeks of TAC. Thereafter, mice were anesthetized with $2 \%$ isoflu- rane, and the extent of pressure overload was measured via a right carotid artery PE-50 catheter connected to a Statham pressure transducer. The animals (TAC vs. sham) were then sacrificed and the lungs, hearts and individual heart chambers were weighed (PW, HW, LVW). Tissue weights were related to body weight (BW) and tibia length (TL).

\section{Results}

In both groups of mice (sildenafil, placebo) 4 weeks of TAC induced significant cardiac, i.e. left ventricular enlargement, as indicated by the necropsy data (TAC vs sham). After 4 weeks of banding, the systolic blood pressure (proximal to the constriction) was lower in sildenafiltreated $(107 \pm 6 \mathrm{~mm} \mathrm{Hg})$ than in placebo-treated mice $(126 \pm 8 \mathrm{~mm} \mathrm{Hg})$. In spite of this, the average HW/BW and $\mathrm{LV} / \mathrm{BW}$ ratios were greater in sildenafil- than in placebo-treated banded mice (HW/BW: $7.3 \pm 0.7$ vs $6.4 \pm 0.2$; LVW/BW: $5.8 \pm 0.4$ vs $5.1 \pm 0.1$, respectively). Also, pulmonary wet weights were increased in the former (PW/ BW: $7.4 \pm 1.4$ vs. $5.6 \pm 0.1)$. Similar data were obtained after normalizing tissue weights to TL. Echocardiography studies at 4 weeks of TAC demonstrated that ejection fractions (EF) and fractional shortening (FS) on average were lower in sildenafil- than in placebo-treated banded mice. 


\section{Discussion}

Unexpectedly, in our ongoing study we could not observe the cardiac protective effects of sildenafil which were previously published. On the opposite, PDE5 inhibition by chronic sildenafil treatment seemed to increase the propensity to pressure overload - induced chamber dilatation and cardiac failure. The mechanism(s) accounting for this deleterious effect is presently unknown. Interestingly, recent studies in isolated adult rat cardiomyocytes suggested that PDE5 controls the soluble (sGC - derived) but not the particulate (GC-A - dependent) cGMP pool, whereas the latter is under the exclusive control of PDE2 [2]. The NO/sGC/cGMP system not only exerts antihypertrophic but also negative metabolic as well as inotropic effects and opposes most of the positive effects of cAMP on cardiac function $[3,4]$. Hence, our future studies will be directed to elucidate whether an enhancement of the $\mathrm{NO} /$ sGC/cGMP-signalling pathway by PDE5 inhibition under certain stress conditions such as pressure overload, might accelerate cardiac dysfunction.

\section{Acknowledgements}

Supported by Deutsche Forschungsgemeinschaft (SFB 487).

\section{References}

I. Takimoto E, Champion HC, Li M, Belardi D, Ren S, Rodriguez, Bedja D, Gabrielson KL, Wang Y, Kass DA: Chronic inhibition of cyclic GMP phosphodiesterase 5A prevents and reverses cardiac hypertrophy. Nature Med 2005, I I:2 I 4-222.

2. Castro LRV, Verde I, Cooper DMF, Fischmeister R: Cyclic Guanosine Monophosphate Compartmentation in Rat Cardiac Myocytes. Circulation 2006, I I 3:2221-2228.

3. Takimoto E, Champion HC, Belardi D, Moslehi J, Mongillo M, Mergia E, Montrose DC, Isoda T, Aufiero K, Zaccolo M, et al.: cGMP Catabolism byPhosphodiesterase 5 A Regulates Cardiac Adrenergic Stimulation by NOS3-Dependent mechanism. Circulation Res 2005, 96: 100-109.

4. M Shah: Divergent roles of endothelial nitric oxide synthase in cardiac hypertrophy and chamber dilatation? Cardiovascular Res 2005, 66:421-422.

\section{Publish with Bio Med Central and every scientist can read your work free of charge}

"BioMed Central will be the most significant development for disseminating the results of biomedical research in our lifetime. " Sir Paul Nurse, Cancer Research UK

Your research papers will be:

- available free of charge to the entire biomedical community

- peer reviewed and published immediately upon acceptance

- cited in PubMed and archived on PubMed Central

- yours - you keep the copyright

Submit your manuscript here:

http://www.biomedcentral.com/info/publishing_adv.asp 